Association for Information Systems

AIS Electronic Library (AISeL)

WHICEB 2015 Proceedings

Wuhan International Conference on e-Business

Summer 6-19-2015

\title{
How to Counteract Negative Effect of Adverse Selection in Chinese E-Commerce Market? Comparative Analysis on Credit Scoring System and Guarantee System of TAOBAO
}

Yong Pan

School of E-Commerce and Logistics Management, Henan University of Economics and Law, China, panyong126@126.com

Follow this and additional works at: http://aisel.aisnet.org/whiceb2015

\section{Recommended Citation}

Pan, Yong, "How to Counteract Negative Effect of Adverse Selection in Chinese E-Commerce Market? Comparative Analysis on Credit Scoring System and Guarantee System of TAOBAO" (2015). WHICEB 2015 Proceedings. 47.

http://aisel.aisnet.org/whiceb2015/47

This material is brought to you by the Wuhan International Conference on e-Business at AIS Electronic Library (AISeL). It has been accepted for inclusion in WHICEB 2015 Proceedings by an authorized administrator of AIS Electronic Library (AISeL). For more information, please contact elibrary@aisnet.org. 


\title{
How to Counteract Negative Effect of Adverse Selection in Chinese E-Commerce Market? Comparative Analysis on Credit Scoring System and Guarantee System of TAOBAO
}

\author{
Yong Pan $^{1}$ \\ School of E-Commerce and Logistics Management, Henan University \\ of Economics and Law, China
}

\begin{abstract}
E-commerce transactions have a rapid development because of its convenience and flexibility. However, compared to the traditional market, the e-commerce transaction still could not get rid of information asymmetry between the online sellers and online buyers. Adverse selection problems brought by information asymmetry have negative impact on e-marketing and reduce the efficiency of the online transaction. Now some trading online platforms such as TAOBAO (http://www.taobao.com) are seeking ways to reduce adverse selection. Widely used approaches are credit scoring system and guarantee system. This paper takes transaction data from $U$ disk market in TAOBAO as samples and analyzes the role of credit scoring system and guarantee system in Chinese e-commerce market. The results showed that the credit scoring system and guarantee system can effectively counteract negative effect from the adverse selection problems. Although the credit scoring system has a significant impact on transaction volume; guarantee system has greater impact on the trading volume than the credit scoring systems. In addition, relationship between the guarantee system and credit scoring system are not substitutes but complement for each other. In the case of the existence of the guarantee system, online consumers' purchase for online goods options is still subject to the impact of the credit scoring system. The paper proposes strategy recommendations to improve credit scoring system and guarantee systems to promote the efficiency of online transactions.
\end{abstract}

Keywords: credit scoring system, guarantee system, adverse selection

\section{INTRODUCTION}

Adverse selection means the selection by the consumer when faced with the circumstance of asymmetric information. Adverse selection theory was suggested by the American economist George Akerlof (1970), who is one of Nobel Economics Prize laureates in 2001. This theory initiated from 'lemons' problem (a colloquialism for defective cars in American), which was also known as 'lemons market' theory. With the adverse selection model, Akerlof indeed explains many economic institutions and many important aspects of uncertainty. Adverse selection theory illustrates the result of asymmetric information: adverse selection leads to decline of market efficiency and market economy is not sufficiently effective ${ }^{[1]}$. He has put forward and explained the approaches for eliminating the adverse selection problem. The Akerlof's adverse selection theory studies the traditional markets (physical markets), but how about the cyber markets that are based on the Internet?

Compared with the physical market, the advantage of e-commerce markets lies in its lower enter-obstacle, lower transaction cost and easily acquirement for the market information. But the adverse selection problem is then actually reinforced by Internet. The adverse selection problems resulting from asymmetry of quality information exist more seriously than in the physical market ${ }^{[2][3]}$. Further, the information provided by suppliers pursuing a differentiation strategy rather deters the possibilities of comparing offers.

In fact, Chinese consumers have stronger “lemon's sensitivity' than other developed countries. According to 'The 35th Statistical Survey Report on the Internet Development in China' released by the China Internet

\footnotetext{
${ }^{1}$ Corresponding author. Email: panyong126@126.com
} 
Network Information Center (CNNIC) $(2011)^{[4]}$, the ratio of Chinese online consumer to encounter fraud is $12.6 \%$, the online shopping rate in China e-consumers was only 55.7\% in 2014.In contrast, the online shopping rate in USA was as high as $71 \%$ in August 2006. These facts illustrate that there exist the adverse selection problems, which has seriously affected the development of the Chinese electronic commerce.

Some trading platforms such as TAOBAO are seeking ways to reduce adverse selection, which is widely used approach to credit evaluation. This system of operating principle is: When buyers and sellers have completed a transaction, the buyer will make the evaluation to the seller's product quality and quality of service after getting the goods, the evaluation is displayed in the seller's shop in the form of scoring, future buyers purchasing goods buyers can check the seller's appraisal records by credit scoring systems. If the seller's credit record is good, more and more buyers will choose to transact with it; if the evaluation is not good, the buyers will interrupt the transaction. This can motivate businesses to take account of long-term interest of maintaining good credit history.The guarantee system is actually a deposit system. If the seller participated in a guarantee system and the merchandise are out of the corresponding problem, buyers can spend seller guarantees in advance, so that the interests of buyers can get maximum protection. For buyers have participated guarantee system, if the seller offers a low-quality product or receivable is not shipped, consumers will initiate complaints against trading platform providers such as TAOBAO and make payment requirements. If the seller is confirmed violations, the platform will be entitled to give the seller the appropriate punishment. Because of this guarantee system is more severe punitive measures, it making the fraudulent sellers have to pay more dearly. Once the seller have participated guarantee systems, they will be no incentive to deceive consumers.

The focus of this paper is: In Chinese e-commerce market, guarantee system is more effective than the credit rating system? Credit scoring system still has a significant effect on transaction under the guarantee system? How to improve the two systems? There is an alternative or complementary one? How to improve the utility of these two systems?

\section{LITERATURE REVIEW}

The earliest use of the credit rating system is a famous site eBay in USA. The design and effectiveness of online transactions credit system has been the focus of many scholars. Ba and Pavlou have proved that the seller's credit score can effectively reduce the network market information asymmetry ${ }^{[5]}$. Dewally and Ederington find that businesses credit score has a significant positive impact on commodity prices, while negative feedback will result in the seller Recently lower commodity pricing ${ }^{[6]}$. Jie collected transaction records about iPod on the eBay auction and have reached similar conclusions using regression analysis methods ${ }^{[7]}$.

Levin draw the conclusion that seller's credit has significant enhance on the auction prices and the negative feedback has negative impact on the transaction price ${ }^{[8]}$. Mikhail and Aim then improved auction model for eBay coins prices further and got the same results ${ }^{[9]}$. Zhou and Zhang found that the credit scoring system has a significantly positive effect evaluation on credit transaction prices and auction success probability, credit evaluation on trading volume (probability) and prices have a positive role in promoting ${ }^{[10]}$.

Although most of the empirical research show that the seller's credit score has a significant positive effect on the transaction price and transaction probability, but there are still some economists' doubt about its effectiveness and it cannot prevent fraud and online transactions effectively. Resnick have analyzed the credit scoring system of eBay and found that the accumulation of the seller's poor record have an impact on the future. So the seller has incentive to use credit scoring system for speculation and fraud ${ }^{[11]}$. Resnick and Zeckanser found that the credibility of the evaluation results will be greatly reduced because the online subject is not identifiable and the credit scoring system cannot be supervised ${ }^{[12]}$. Wooders believes that online sellers with well credit score may not provide a high quality product or service because of the credit scoring system has 
certain distortion ${ }^{[13]}$. Pan has made an empirical study of credit scoring system from TAOBAO and found that the credit scoring system can play an important role to reduce the adverse selection phenomenon of lacking credit network market, but the distortion of Web information issuance will reduce the effect of credit scoring system ${ }^{[14]}$.

Because of these problems of credit scoring system, some scholars begin to study trust guarantee system. Koreto verified that the third-party guarantee services can significantly increase the consumer's purchase intention with the mathematical model ${ }^{[15]}$. Lee put out that the introduction of third-party guarantee system can effectively reduce the asymmetric information in network ${ }^{[16]}$. Dewally has validated the conclusion by using eBay data ${ }^{[17]}$. Heezena and Baetsbyc analyzed guarantee system of the network platform in Holland's online flower market ${ }^{[18]}$. Choi, Stah and Whinston believe that short-term contract in the Internet exchange market can guarantee the integrity management ${ }^{[19]}$. Changsu makes the summary on the evolutionary way for Internet shopping platform and believed that the guarantee system is effective to solve the problem of information asymmetry ${ }^{[20]}$. Pan have taken the network reputation as a guarantee system and established a reputation model using the principle of information economics ${ }^{[21]}$. Chen believes that the certification as a guarantee system can reduce the generated fraud ${ }^{[22]}$.Zhou and Lu questionnaire for the role of third party trust system and consider the supervision and guarantee measures have important effect ${ }^{[23]}$.

This paper will be based on the local characteristics and study how to offset negative impact from adverse selection problems in Chinese e-commerce market. The paper will be based on evidence of TAOBAO and comparatively analyze credit scoring system and guarantee system.

\section{EMPIRICAL ANALYSIS: BASED ON THE DATA FROM TAOBAO}

\subsection{TAOBAO credit scoring system and guarantee system}

TAOBAO (http://www.Taobao.com) was founded in 2003 by Alibaba Company. TAOBAO has exceeded eBay and become China's largest C2C online trading platform in 2005. In order to reduce the negative effect of adverse selection of virtual transactions, TAOBAO has established a set of credit scoring system, records each user's evaluation acquired in the past transactions, these evaluations has been changed into a total reputation score in a certain way. Compared with eBay, TAOBAO designs the credit scoring system that is different from the eBay:

- The method of pricing is one-time price instead of bidding. The credit evaluation got by the seller and the buyer has calculated separately. On each month, the evaluation score between buyers and sellers are less than 6 point. The evaluation beyond the scope will not score.

- Evaluation system is dynamic. After successful transactions in the TAOBAO online buyers, buyers can evaluate the seller with four indicators (whether conform to, baby and describe the attitude of the seller, the seller's delivery speed and logistics Services Company), evaluation is divided in 1-5.

- Avoid retaliatory bad evaluation. Buyers can evaluation after purchase, but evaluations are published after the mutual evaluations are finished in order to avoid revenge.

But the TAOBAO found some problems, such as a large number of online credit speculation phenomenon. Some malicious counterfeiters (credit-brusher) take 'fake sales' to get good credit score. Although the TAOBAO uses some severe blow to this kind of behavior, the credit the phenomenon still exists. The main reason is that this credit-brusher simulates real transaction which is difficult to be detected. In addition, there are some distortion behavior such as behavior of malicious evaluation and credit manipulation. Therefore, credit scoring system is difficult to curb Internet fraud effectively. In this case the guarantee systems emerge. TAOBAO pushed out guarantee system based on the 'consumer protection plan' in 2007 and encourage qualified buyers to 
join the system. In the guarantee system the sellers can choose faith deposit to pay a certain amount to the TAOBAO. If the product quality problems arise in after the success of the transaction within 14 days, buyers can initiate payment application in advance from TAOBAO. If buyers suffered disputes or losses and the seller refused to pay, TAOBAO will use the deposit stored in the TAOBAO from the seller to pay the buyer.

\subsection{The data and explanatory variable}

This paper selects $U$ disk (model: DT101 8G) from TAOBAO as the research object, use data capture program provided by TAOBAO server to get relevant data 1242 entries. The research object of this paper is mainly the influence of credit scoring system and guarantee system for network transaction efficiency, so the explanatory variable is the volume of transactions recently 30 days (sales). Explanatory variables are credit evaluation index and guarantee system index. Credit evaluation index include seller credit score (score) and the seller received rate (ratio).

The guarantee system is set as a dummy variable index. We use five indicators from TAOBAO’s guarantee system as explanatory variables: $D 1$ presents whether or not to join the 'consumer protection service', D2 presents whether or not to join the 'seven days to return' service, D3 presents whether or not to support the 'false one compensate three', D4 presents whether or not to join '24 hours delivery', D5 presents whether or not to join '30 days to repair'. Price appears in the model as a control variable.

Table 1. Variable definition

\begin{tabular}{|c|c|c|c|}
\hline Type & Name & Meaning & The expected sign \\
\hline The dependent variable & sales & volume of transactions in 30 days & \\
\hline \multirow{8}{*}{ Variables } & score & seller's credit & + \\
\hline & price & commodity prices & - \\
\hline & ratio & praise rate of seller & + \\
\hline & D1 & consumer protection service & + \\
\hline & $D 2$ & seven days to return & + \\
\hline & D3 & false one compensate three & + \\
\hline & D4 & 24 hours delivery & + \\
\hline & D5 & 30 days to repair & + \\
\hline
\end{tabular}

Table 2. Descriptive statistics of $U$ disk $(\mathrm{N}=762)$

\begin{tabular}{|c|c|c|c|c|c|}
\hline & The average & Median & maximum value & minimum value & Standard deviation \\
\hline sales & 2.36 & 0 & 275 & 0 & 13.21 \\
\hline score & 302 & 219 & 92456 & 0 & 793.87 \\
\hline ratio & $92.90 \%$ & $100 \%$ & $100 \%$ & $0 \%$ & $16.86 \%$ \\
\hline price & 47.54 & 46 & 54 & 43 & 3.62 \\
\hline$D 1$ & 0.5467 & 1 & 1 & 0 & 0.51 \\
\hline$D 2$ & 0.2746 & 0 & 1 & 0 & 0.46 \\
\hline D3 & 0.0069 & 0 & 1 & 0 & 0.08 \\
\hline$D 4$ & 0.0472 & 0 & 1 & 0 & 0.22 \\
\hline D5 & 0.0568 & 0 & 1 & 0 & 0.25 \\
\hline
\end{tabular}




\subsection{Model}

The specific model is as follows:

$\ln ($ sales +1$)=\beta_{0}+\beta_{1} \ln ($ price $)+\beta_{2} \ln (1+$ score $)+\beta_{3} \operatorname{lm}(1+$ ratio $)+\beta_{4} D 1+\beta_{5} D 2+\beta_{6} D 3+\beta_{7} D 4+\beta_{8} D 5+\varepsilon$

Among them, D1-D5 is a dummy variable. Sales, score, ratio and price are taken the natural logarithm form. Because the sample variables have different, the logarithm is designed to eliminate the heteroscedasticity that may exist in regression. Because most logarithm value of the observations is less than 0 , therefore the variables are plus 1 and then take the natural logarithm.

This paper uses the Tobit model to ensure the consistency and unbiased estimation. Specific form as follows:

$\ln ($ sales +1$)=\beta_{0}+\beta_{1} \ln ($ price $)+\beta_{2} \ln (1+$ score $)+\beta_{3} \ln (1+$ ratio $)+\beta_{4} D 1^{*} \ln (1+$ score $)+\beta_{5} D 2^{*} \ln (1+$ score $)+\varepsilon$

\subsection{Data analysis}

According to the discussion above, we have designed a credit score on sales, the guarantee system of effect on sales, two kinds of trust system on sales and the effects of interaction between two systems. The price in each model is control variables. The four models under the Eviews5.0 operation results are summarized as follows:

Table 3. Analysis results

\begin{tabular}{|c|c|c|c|c|}
\hline \multirow[b]{2}{*}{ Variables } & \multicolumn{4}{|c|}{ Variables $\ln ($ sales +1$)$} \\
\hline & Model 1 & Model 2 & Model 3 & Model 3 \\
\hline $\ln ($ price $)$ & $-5.79 * * *$ & $-5.62 * * *$ & $-5.54 * * *$ & $-5.37 * * *$ \\
\hline $\ln (1+$ score $)$ & $0.18^{* * *}$ & - & $0.14^{* * *}$ & $0.28 * *$ \\
\hline $\ln (1+$ ratio $)$ & $0.12 *$ & - & $0.11^{*}$ & 0.07 \\
\hline D1 & - & $1.22 * * *$ & $0.35^{* *}$ & $0.29 * *$ \\
\hline D2 & - & $0.98 * * *$ & $0.37 * * *$ & $0.31^{* *}$ \\
\hline D3 & - & -0.63 & -0.43 & - \\
\hline D4 & - & $0.23 *$ & 0.16 & - \\
\hline D5 & - & 0.36 & $0.21^{*}$ & - \\
\hline$D 1^{*} \ln (1+$ score $)$ & - & - & - & -0.05 \\
\hline$D 2^{*} \ln (1+$ score $)$ & - & - & - & $-0.22 * *$ \\
\hline$C$ & $38.61^{* * *}$ & $42.53^{* * *}$ & $36.75^{* * *}$ & $35.93^{* * *}$ \\
\hline$R^{2}$ & 0.58 & 0.74 & 0.86 & 0.85 \\
\hline Hierarchical F-test & & & $20.35 * * *$ & $24.52 * * *$ \\
\hline Durbin-Watson stat & & & 1. 81 & 1.87 \\
\hline
\end{tabular}

( $*$ 、**, *** are expressed in $10 \%, 5 \%$ and $1 \%$ significance level)

From this analysis we can found:

- Prices in the four models of on the impact of explanatory variables are significant and the coefficient is negative. It indicates that the higher the price of goods more difficult to sell. Because the buyer fails to identify the quality, only the high quality goods receiving low price -- this is characteristics of adverse selection. The results show that online consumers' first value is the price of commodity in Chinese e-commerce market. The results also indicate that Chinese online consumers is more sensitive to price.

- Credit evaluation in this model is also significantly affects on the explained variable even in the presence of guarantee system. This shows that credit scoring system can weaken the negative effect of adverse selection 
on TAOBAO. This result also reflects the defects of credit scoring system: when the seller's credit score is high enough, the seller still may engage in fraud because little review does not significantly influence the positive score. This situation will lead to fuzzy evaluation and lose their effectiveness. On the other hand, it also results in one-sided pursuit of credit points from sellers.

- The guarantee system of variables $D 1$ and $D 2$ had a significant effect on sales. The results show that, 'the consumer protection service' and 'returned 7 days service' in several models have significant influence on the sales of goods. It also indicate that the sellers who have joined 'the consumer protection service' and 'returned 7 days service' can reduce the risk of online shopping.

- The guarantee system of the variables D3 and D4 had a small significant effect on sales. The reason of the effect is: sellers to join the security services is few, the use of this service businesses is less than $1 \%$. In addition, if the buyers buy fake and appeal to TAOBAO, this system requires many businesses to provide products and expected costs is higher. The service guarantees such as the 24 hour delivery and 30 days of repair is not significant, which mainly due to buyers' focus on the quality of the goods first. Also the 24 hours delivery this guarantee service has some alternative, dynamic evaluation system has few significant roles.

- We compare the effect of credit scoring system and guarantee system on trading volume. By calculation we found: when the credit score increase from the 302 to 604 , seller only sale more than $1.2 U$ disks in 30 days; Sellers joined the consumer protection plan can sell more $4.8 U$ disk than not to join the 30 day; Sellers joined the 7 days return plan can sell more $4.8 U$ disk than not to join the 30 day. Through the above analysis, we can conclude that although credit score has significant influence on trading volume, guarantee service greater impact on trading volume than the credit score.

- The correlation between credit scoring system and guarantee system. By the model results, the $D 1^{*} \ln (1+$ score $)$ coefficient is negative but not significant, it indicating that whether the seller join the consumer protection service, credit evaluation has impact on trading volume and there is little difference significant. Even if sellers joined the consumer protection service, credit evaluation still has remarkable effect on the trading volume, also that buyers pay more attention to credit scoring. $D 2 * \ln (1+s c o r e)$ coefficient is negative and more significantly, it shows that comparing with adding 7 days return service buyers, credit scoring effect on the trading volume has less significantly than that not to join the service. In addition, the $F$ test results show that: the sum of three variable coefficient $\ln (1+$ score $), D 1^{*} \ln (1+$ score $), D 2 * \ln (1+$ score $) \quad(t=0.10)$ are no significant difference from zero. It shows that credit scoring system have no significant impact on trading volume for the sellers joined the seven day return service. Buyers don’t need to take the credit score system as a reference.

The above results also tell us, credit evaluation system and guarantee system has a complementary relationship. For the sellers joined consumer protection services credit evaluation for buyers still has a significant positive effect. So the consumer protection service cannot completely replace the credit evaluation function. By the 80 online sellers random sampling from TAOBAO and credit evaluation record in 30 days, we found that nearly $15 \%$ sellers have received negative feedback in the comments. The complaint is small flaws or service. If the buyer request compensation, they must collect relevant evidence such as the seller chats, the pictures of goods, according to the consumer protection service process. It will spend some time and energy. Online buyers have to wait for about 30 days before applying for reimbursement success. If some quality problems are not too serious, online buyers may not apply for compensation because of the high cost and may choose to give bad scoring or comment to warn the seller, which still needs credit scoring system to compensate for the loss. 


\section{CONCLUSION}

Through the empirical analysis, we can find that the credit scoring system and guarantee system are conducive to reduce negative effects brought by the adverse selection. While credit scoring system has significant influence on transaction volume, the influence of guarantee system on trading volume was much higher than that of credit scoring system. But guarantee system cannot completely replace the credit evaluation function, it is a complementary relationship. In the presence of guarantee system, consumers are still subject to credit scoring system.

In order to make better use of these two kinds of systems counteract the adverse selection, following aspects should be improved:

- The threshold of the seller for guarantee system should be reduced. We should improve the cognitive on the guarantee system and simplify application process for sellers to join guarantee system. New seller should be equal to get competition opportunity with the old seller under the guarantee system.

- Since credit evaluation system and guarantee system has a complementary relationship, forced credit score rule or automatically processing system should be canceled when the buyer does not score. We should allow the buyer make voluntary score after completion of the transaction.

- Credit scoring system need to be improved and revised to promote guarantee system operates better. Although TAOBAO's information-gathering and transmission of credit scoring system is carried out by the auto-complete, this information is made by the traders of their own. It will cause the 'speculation' of credit with false transactions, or buyers and sellers flatter or even revenge each other. Therefore, to prevent the seller using false transactions to 'speculate' credit is very important. We are pleased to see that TAOBAO has recognized this problem and take relevant measures, such as stipulating evaluation points between buyers and sellers not more than 6 points each natural months, adopting the real-name and increase punishment (or even the concealing ID) and other measures. But the effect is still not ideal. With the e-commerce policy and regulations gradually become clear and mature, we will counteract negative effect of adverse selection in Chinese e-commerce market for more options.

\section{ACKNOWLEDGEMENT}

This research was supported by the National Social Science Foundation of China under Grant 10BGL096.

\section{REFERENCES}

[1] Akerlof G. A.(1970). The Market for 'Lemons’: Quality Uncertainty and the Market mechanism. Quarterly Journal of Economics, 84(4): 488-500

[2] Pan, Y. (2005).Cyber 'Lemon' Problem and E-Consumer's Behavior Model. The Seventh Wuhan International Conference on e-business. Alfred University Press, Vols 1-4:2519-2524

[3] Pan, Y. (2012). Channel Conflicts and Market Segments between E-Commerce Market and Traditional Market: Based on the Adverse Selection Perspective. International Journal of Networking and Virtual Organizations, 11(3/4):305-314

[4] China Internet Network Information Center (CNNIC).(2015).China Statistical Survey Report on Popular Internet Issues, http:// www.weste.net/2015/02-03/101478.html (in Chinese)

[5] Ba S, Paul A. (2002). Evidence of the Effect of Trust Building Technology in Electronic Markets: Price Premiums and Buyer Behavior. MIS Quarterly, 26(3):243-68

[6] Dewally M, Ederington, L. (2006). Certification, Warranties and Information as Remedies for Seller and Buyer Information Asymmetries: Lessons from the Online Comic Book Market. Journal of Business, 34(12):324-337.

[7] Zhang J. (2006). The roles of players and reputation: Evidence from eBay online auctions. Decision Support System, 32(42):1800-1818. 
[8] Levin D. (2005). Demand Reduction in Multi-Unit Auctions: Evidence from a Sportscard Field Experiment: Comment. American Economic Review, 95(1):467-471.

[9] Melnik I, Mikhail, Aim J.(2005). Seller Reputation, Information Signals, and Prices for Heterogeneous Coins on eBay. Southern Economic Journal, 72(2): 305-328.

[10] Zhou L., Zhang W., Gu Q., Shen Y. (2006).The value of reputation: an example. Economic Research. 23(12): 82-92+125(in Chinese).

[11] Resnick.(2002).The Value of Reputation on eBay: A Controlled Experiment. KSGWorking Paper, No.RWP03-007.

[12] Resnick P, Zeckhauser R,Friedman E,etal. (2004). Reputation systems .Communications of the ACM , 43(12): 45-48.

[13] Wooders J. (2006). Reputation in auctions: theory and evidence from eBay. Journal of Economics \&Management Strategy, 15(2):146-161

[14] Pan, Y. (2009). 'Lemon’ Problem and Counteracting System in Chinese E-Commerce Market: Based on the Data from TAOBAO. The Eighth Wuhan International Conference on e-business.Alfred University Press, Vols 1-4: 1982-1989

[15] Koreto R. (1997). In CPAs we trust, Journal of Accountancy, 56(6):62-64

[16] Lee. (2009). Pre-Bonding Method using Self-Alignment Effect for Multichip Packaging. International Symposium on Assembly and Manufacturing, 54(8):347-263

[17] Dewally M, Ederington L. D. (2006). Reputation, Certification, Warranties, and Information as Remedies for Seller and Buyer Information Asymmetries: Lessons from the Online Comic Book Market. Journal of Business, 79(2):693-730

[18] Heezena J, Baetsbyc W. (1996). Case study the impact of electronic markets: the case of the Dutch Rower Auctions. Journal of Strategic Information Systems, 44(5):587-596

[19] Choi, S.Y., Whinston, A.B. (1997).Intermediation,Contracts and Micro payments in Electronic Commerce. Electronic Markets Newsletter, 23(4):208-231

[20] Changsu K. et al (2007).Evolution of Web-Based Shopping Systems: Characteristics and Strategies. Journal of Electronic Commerce in Organizations, 5(4):70-87

[21] Pan, Y. (2011).Eliminating the cyber 'lemons' problem with the e-reputation in e-commerce market: theoretical model and practice.International Journal of Networking and Virtual Organisations, 8(3/4):182 - 191

[22] Chen X. (2006). On the certification and accreditation under the conditions of market economy to eliminate market failure, Maintain the market stability and the role of the. China testing technology, 32(1):71-73. (in Chinese)

[23] Zhou T., Lu Y. (2008). An empirical analysis on the role of third party trust system of C2C transactions. Industrial engineering and management, 23(3):104-110. (in Chinese) 